
\title{
28 Research Square \\ The Controversial Role of Folic Acid on Diabetic Auditory Neuropathy
}

\section{Aida Doostkam}

Shiraz University of Medical Sciences

\section{Hossein Mirkhani}

Shiraz University of Medical Sciences

Kamyar Iravani ( $\sim$ iravanika@sums.ac.ir)

Shiraz University of Medical Sciences https://orcid.org/0000-0001-8302-2683

\section{Saied Karbalay-Doust}

Shiraz University of Medical Sciences

\section{Afsaneh Doosti}

Shiraz University of Medical Sciences

\section{Elham Nadimi}

Shiraz University of Medical Sciences

\section{Research Article}

Keywords: Auditory brainstem response, Auditory neuropathy, Diabetes mellitus, Folic acid, Stereology

Posted Date: October 18th, 2021

DOl: https://doi.org/10.21203/rs.3.rs-884001/v1

License: (c) (1) This work is licensed under a Creative Commons Attribution 4.0 International License. Read Full License 


\section{Abstract}

\section{Purpose}

Diabetic auditory neuropathy(DAN) is a common complication of diabetes that seriously affects the quality of life in patients. In this study, we investigate the role of folic acid in the treatment of DAN in an experimental rat model.

\section{Methods}

Thirty-two Sprague-Dawley rats were equally divided into 4 groups: group 1, normal; group 2, diabetic rats; group 3and 4, rats treated with folic acid (40 and $80 \mathrm{mg} / \mathrm{kg}$, respectively). The tools we used in this study to investigate the effect of folic acid on DAN were auditory brain stem response, stereology methodfor estimation of the volume and number ofspiral ganglion,volume of stria vascularis, and spiral ligament, and measurement of homocysteine (HCY), malondealdehyde(MDA) and superoxide dismutase.

Results

Our study showed that folic acid treatment was not significantly effective in improving structural and functional disorders in DAN, despite its effect in reducing $\mathrm{HCY}$ and MDA as oxidative biomarkers.

Conclusion

Folic acid is not effective in relieving morphological and functional disorders in DAN.

\section{Introduction}

Diabetic neuropathy is a common complication of diabetes mellitus(DM), which affects the sensory, motor and autonomic nerves and in some cases the central nervous system[1-3]. Ischemia caused by damage to the feeding vessels of the nerves in diabetic patients causes neural fibers demyelination, degeneration and the resulting neuropathy[2,4].

The major metabolic disorders that cause vascular damage in diabetic patients, followed by neuropathy, are mainly due to polyol pathway and oxidative stress, which increase free radicals, especially reactive oxygen species in the tissues[4-6].

Impaired neural microcirculation in the auditory system can cause morphological and functional disorders. Diabetic auditory neuropathy (DAN) ismainly accompanied by debilitating symptoms such as hearing loss, tinnitus and dizziness[7,8].

Due to the significant occurrence of neuropathy, as well as its auditory type in diabetic patients, various agents have been evaluated for prevention and treatment of neural damage inexperimental and clinical studies. Among the drugs that have been investigated for diabetic neuropathy, rutin[9], folic 
acid[10,11],alpha-lipoic acid[12] and benfotiamine(a vitamin B1 derivative) can be mentioned[13]. The results of these investigations are not sufficient for clinically acceptable applications and results.

In a study conducted by the authors of this article on rutin in the prevention and treatment of diabetic auditory neuropathy in rats, theuseful effect of this drug in terms of morphological and functional improvement was defined to some extent[9].

One of the drugs under investigation which is relatively more clinically used than others in diabetic neuropathy isfolic acid. Due to the discrepancies in animal and clinical studies and clinical observations that in some cases show the ineffectiveness of this drug, we set out to do an investigation about folic acid effectiveness against diabetic auditory neuropathy in rats, following our previous study on rutin.

In this study, auditory brain stem response(ABR), stereology of spiral ganglion,homocysteine (HCY), superoxide dismutase(SOD), and malondialdehyde(MDA)levels were used as defining criteria toinvestigate the effect of folicacid treatment in DAN.

Folic acid (vitamin B9) is categorized as a water-soluble vitamin which is involved in the synthesis of genetic materials, the production of red blood cells and fetal health. Folic acid is asynthetic form of folate that is better absorbed than folate. The main sources of folate include leafy vegetables, citrus fruits, mushrooms, grains and liver[14,15].

Folate, as a donor of single carbon units, is involved in the synthesis of serine from glycine, nucleotides from purine precursors, and in the formation of deoxy thymidylate monophosphate. In addition to its role in the synthesis of DNA and messenger RNA, it acts as a methyl donor to produce methyl cobalamin, which is used in the remethylation of HCY to methionine[16,17].

Folic acid seems to have the potential ability for growth and differentiation of neural cells and also hasa neuroprotectiveproperty due to its effects on $\mathrm{HCY}$ metabolism as well as decreasing malondialdehyde levels and increasing the expression of nerve growth factors[18,19].

$A B R$ is one of the best tools for evaluating auditory neuropathy functionally. In this method, the evoked electricalactivities in the auditory nerve and its brainstem connections are measured. Diabetes mellitus can cause changes in ABR potentials latency and waveforms by disrupting the microcirculation of the auditory pathway[7,20].

Impaired microcirculation in DAN and subsequent cochlear ischemia can cause morphological changes in the hair cells, spiral ganglion, spiral ligament and stria vascularis[7]. In this study, we used the stereology method in the spiral ganglion, spiral ligament,and stria vascularis to examine morphological changes in the DAN and the response to treatment by measuring the volume and number of cells.

$\mathrm{HCY}$ is a non-proteinogenic amino acid made from the amino acid methionine following a transmethylation reaction. Many studies have shown an association between high levels of HCY in diabetic patients and its vascular and neurological complications[21-23]. 
SOD is an antioxidant enzyme that catalyzes the dismutation of superoxide radicals into oxygen and hydrogen peroxide. This enzyme acts as a biomarker in antioxidant activity in controlling oxidative stress [24].

MDA is a product of polyunsaturated fatty acids peroxidation. MDA is considered as a reliable biomarker in oxidative stress measurement levels in many experimental and clinical studies $[25,26]$.

In this study, ABR was used to evaluate the hearing function, the stereology method for morphological evaluation in the spiral ganglion and oxidative biomarkers of HCY, MDA, and SODlevels as tools to evaluate the efficacy of folic acid treatment on DAN.

\section{Materials And Methods}

\section{Materials}

Folic acid andStreptozotocin (STZ) werepurchased from Sigma-Aldrich Chemical Company (Steinheim, Germany).

\section{Animals preparation}

Thirty-two male Sprague-Dawley rats (250-300 g) wereobtained from the Center of Comparative and Experimental Medicine (Shiraz, Iran). The rats were kept under standard lighting (12 hour-light/dark cycles), humidity $(25-35 \%)$, temperature $\left(22-26^{\circ} \mathrm{C}\right)$ per day and had free access to food and water. The rats were randomly allocated to four groups of eight rats, including non-diabetic normal rats with distilled water (Normal group), type 1 diabetic rats with distilled water without folic acid treatment (DM group), type 1 diabetic rats that received folic acid (40 mg/kg/day) (DM+FA40group), and type 1 diabetic rats that received folic acid ( $80 \mathrm{mg} / \mathrm{kg} /$ day) (DM+FA80group).

The experimental procedures were approved by the Ethics Committee of Shiraz University of Medical Sciences (Ethic code: IR.SUMS.REC.1397.459).

\section{Induction of type 1 diabetesmellitus}

To induce type 1 diabetes mellitus, a single intraperitoneal administration of STZ $(60 \mathrm{mg} / \mathrm{kg})$ was dissolved in cold citrate buffer andinjected into animals. Three days after induction, fasting blood sugar (FBS) levels were checked using a Glucometer (Accu-check ${ }^{\circledR}$, Germany), and rats with FBS levels greater than $300 \mathrm{mg} / \mathrm{dL}$ were considered as type 1 diabetic animals[27]. The confirmation day was considered 3daysafter STZ injection.

\section{Treatment}

After the confirmation of diabetes, two groups received an oral solution of folic acid $(40 \mathrm{mg} / \mathrm{kg} / \mathrm{day}$, DM+FA40group) and ( $80 \mathrm{mg} / \mathrm{kg} /$ day, DM+FA80group) by gavage once a day for 8 weeks. Normal and Diabetic groups received an equal amount of distilled water. 
After 8 weeks of treatment, rats wereprepared for auditory assessment by ABR and histological studies.

\section{ABR assessment}

At the end of treatments, Xylazine $(10 \mathrm{mg} / \mathrm{kg})$ and Ketamine $(75-100 \mathrm{mg} / \mathrm{kg})$ were administered to the rats via intraperitoneal injection[9]. Thermal blanketand heat lampwere used to avoid hypothermiaduring anesthesia. In the ABR recording,groundelectrode (ECG Ambu Blue Sensor, Penang, Malaysia) was fixed on the dorsal neck of rat. Also, active electrode $(+)$ and the reference electrode $(-)$ were attached to the forehead and post auricular area of right and left ears, respectively. Evoked potentials were achieved by intra acoustic EP25 (Copenhagen, Denmark) system with OtoAccess software (Middelfart, Denmark) after releasingclicks to the right ear via embedded earphones. Minimum 700 stimuli at a rate of $11.1 \mathrm{~Hz}$ were distributed to right ear and electrode impedance was below $3 \mathrm{~K} \Omega$. ABR evaluations were accomplishedusing band pass filter of $100-3,000 \mathrm{~Hz}$ and time window of $10 \mathrm{~ms}$ [28]. Evoked potentials were estimated according to the following parameters: absolute latencies and wave morphology of wave's II and Vand hearingthreshold. Hearing threshold was detected in $5 \mathrm{~dB}$ steps decliningfrom maximum stimulus of $70 \mathrm{~dB}$ until wave patterns morphology disappeared.

\section{Tissue preparation\& stereological analysis}

\section{Preparation of inner ear in rat}

At the end of study, all of the animals were sacrificed after induction of deep anesthesia by intraperitoneal injection of $100 \mathrm{mg} / \mathrm{kg}$ Ketamine and $10 \mathrm{mg} / \mathrm{kg}$ xylazine[9]. Thetemporal bone was carefully dissected and separated from skullbones, decalcification of temporal bone was performed by use of $8 \% \mathrm{HCL}$ and $8 \%$ formic acid for 3days[29]. All temporal bones underwent tissue processing and after that were embedded in paraffin wax. The paraffin blocks were cut into2 $5 \mu$ m thickness serial section together with the external acoustic meatus axis by a microtome (Microme, Germany). All of the serial sections of cochlea were collected and separated from apical to basal cochlear.

Thirty-two to thirty-six sections of cochlear tissue per rat were obtained and all slides were stained with Hematoxylin and eosin. Afterward, 8-12 sections of the 32-36 sections of cochlea in a systematic uniform random sampling were selected. The first section was randomly selected and the next sections were chosen at equal intervals.

Stereological techniques were applied to estimate the volumes of the spiral ganglion,spiral ligament and striavascularis and the number of neurons in spiral ganglion. The cochlear sections evaluation was done by an examiner who was blind to the animal groups.

\section{Estimation of the spiral ganglion, spiral ligament and striavascularis volumes}

The live figure of each cochlea section was evaluated by a video microscopy system and the stereology software (StereoLite, SUMS, Shiraz, Iran). 
Regions of the selected structure (spiral ganglion, spiral ligament, and stria vascularis) were recognized in each cochleasection(Fig. 1a). The volume of the selected structure was analyzed by the point-counting methods based on "Cavalieri's principle" at the final magnification of 20 on 8-12 sections per animal[3032].

The probe of stereology (a grid of points) was overlaid on thecochlear images(Fig. 1b), the crosssectional area of the selected structure " $\sum A^{\prime \prime}$ was calculated by the stereology software. Then the crosssectional area of the selected structure " $\sum A^{\prime \prime}$ was multiplied by the distance between the $\operatorname{sections}(T)$. The volume of selected structure was estimated by the following formula:

$\mathrm{V}=\mathrm{T} \cdot a / p \cdot \sum \mathrm{P}$

where $\mathrm{V}$ is the volume of selected structure; $\mathrm{T}$ is distance between two selected sections; $a / p$ is area per point; and $\sum P$ is total points hitting selected structure. The area per point $(a / p)$ was $722500(850 \times 850)$ $\mu \mathrm{m}^{2}$ and an average of 121 points were counted per animal.

\section{Estimation of the neuronnumbers in the spiral ganglion}

The spiral ganglion is a collection of bipolar neuron cell bodies in the modiolus of inner ear, the lemon-like shaped central axis of the cochleawhose fibers innervate the corti organ[30].One of the stereological techniques for spiral ganglion neuronscounting inahistological section thickness is the optical dissector[32-34].

The site of the microscopic field was chosen by moving the stage in directions ( $x$ and $y)$ at the same distances pursuant to systematic uniform random sampling order. Objective lens (40×, NA 1.30) was employed by oil immersion.

The optical disector is made of several parts.An Eclipse microscope (E200, Nikon, Tokyo, Japan) with a large numerical aperture $(\mathrm{NA}=1.30) \times 40$ oil-immersion objective was linked to a video camera, which conveyed the live image of microscope to a computer monitor, and an electronic microcator with digital readout (MT12, Heidnehain, Traunreut, Germany) for estimating the movements in the Z-axis with a precision of $0.5 \mu \mathrm{m}$.

One of the stereological probes isunbiased counting frame that is employed to count the number of select cells, by a stereology software system (Stereolite, SUMS, Shiraz, Iran). Theunbiased counting frame, composed of two exclusion lines (the lower and left borders and their extensions) and two inclusion lines (the upper and right borders), was overlaid on the live image at final magnification of $1500 \times$ (Fig. 2a).

The guard areas are zones at the superior and inferior part the histological sections. These regions were applied to avoid cutting tissue artifacts that occur throughout tissue processing on these areas of the sections. Any counting incident in focus within the up (the first $3.5 \mu \mathrm{m}$ ) or down guard zones was deleted. 
Each nucleolus cell that came into focus within the guard areas was not counted. The "height of disector" was the distance between the guard areas which was $18 \mu \mathrm{m}$ here.Every nucleolus cell appearing in the focus inside the later focal sampling plane was selected if it was located completely or partially inside the counting frame (Fig. 2b)and did not contact the forbidden lines[32-34].

The numerical density (NV) of the spiral ganglion neurons were evaluated using the following formula:

\section{$\mathrm{Nv}=\left[\sum \bar{Q} /[\mathrm{EP} \times \mathrm{a}(\mathrm{f}) \times \mathrm{h}]\right] \times[\mathrm{t} / \mathrm{BA}]$}

Where " $\Sigma \bar{Q} "$ is the number of the spiral ganglion neuronscoming into high quality focus in disector height, " $\Sigma \mathrm{P}$ " is the total of the counting unbiased frames in all fields of microscopic, and " $\mathrm{h}$ " is the height disector. Where " $a / f$ " is the area of counting frame, " $t$ " was the true section thickness calculated with the microcator, and "BA" is the microtome block advance set. The thickness of the internal ear section was calculated in the whole microscopic fields of view with uniform random sampling order from each section.

On average, 100-200 neurons were counted in 26 disectors in 8-12 sections per animal. The area of the counting frame $(a / f)$ was $1082.41(32.9 \times 32.9) \mu m^{2}$.The real average thickness of the sections was $22 \mu \mathrm{m}$ $(t)$ and " $B A$ " was $25 \mu \mathrm{m}$. The total number of the neurons was estimated by multiplying the numerical density ( $\mathrm{Nv}$ ) by $\mathrm{V}$ (submucosa or muscularis layers).

\section{Biochemical assays}

At the end of treatments, SOD activity, MDA serum levels, and serum activity of HCYwere measured in all groups, using the SOD ELISA kit (Cayman, Ann Arbor, MI, USA), Rat MDA ELISA kit (CusabioBiotech, China), and HCY ELISA kit (Axis Homocysteine Enzyme Immunoassay,IBL, Germany), respectively.

\section{Statistical analysis}

Data were presented asmean for stereological resultsandmean \pm SEM forother results. Statistical analysis was determined using one-way analysis of variance (ANOVA) for parametric data such as latency of wave II, hearing threshold, volume of spiral ganglion, spiral ligament and striavascularis,number of spiral ganglion neurons, SOD, MDA,and HCY.Also,Kruskal-Wallis test was appliedfor nonparametric data such as different forms of wave V. GraphPad Prism software (Version 6) was used to compare data. If a significant difference was obtained, the source of difference was located by Tukey or Dunn post-hoc test. $P<0.05$ was considered as statistically significant.

Table 1. Wave $V$ types inthe normal, diabetic, DM+FA40, and DM+FA80 groups 


\begin{tabular}{|lllll|}
\hline Group & $\begin{array}{l}\text { Wave V } \\
\text { Normal (\%) }\end{array}$ & $\begin{array}{l}\text { Wave V } \\
\text { with delay (\%) }\end{array}$ & $\begin{array}{l}\text { Wave V } \\
\text { Absent (\%) P-value }\end{array}$ \\
& & & & \\
Normal & 100 & 0 & $0<0.0001$ & \\
Diabetic & 0 & 0 & 100 & - \\
DM+FA40 & 12.5 & 0 & 87.5 & 0.99 \\
DM+FA80 & 0 & 37.5 & 62.5 & 0.99 \\
\hline
\end{tabular}

Differences were tested by Kruskal-Wallis and Dunn's post hoc test.All datais in comparison todiabetic group.

\section{Results}

\section{Outcome of folic acidon the function ofABR}

After 8 weeks ofDM induction, theeffect of diabetes on ABR wave forms was observed.

The negativechanges were significantly on the latency of wave II, hearing threshold, andthe presence of wave $\mathrm{V}(P<0.001)$. The latency of wave Il,increasedhearing threshold, andthe rate of presence of wave $\mathrm{V}$ are shown in Fig. 3 and Table 1, respectively.Folic acid (40 and $80 \mathrm{mg} / \mathrm{kg})$ had no significantrecovery effect onABRrecordingsat the end of study (about 8 weeksafter the induction of diabetes) (Fig. 3a, 3b andTable 1).

\section{Stereological studies}

\section{Evaluation of spiral ganglion,spiral ligament, stria vascularisvolume, and Spiral ganglion neuron count}

There is a significant decline in the total volume of the spiral ganglion,spiral ligament,stria vascularis andthe count of spiral ganglion neurons in the rats with DM compared to the normal animals $(P<0.05)$ (Fig. 4a, 4c, 4d, and 4b).

Thetotal volume of spiral ganglion,spiral ligament,stria vascularis andthe number of spiral ganglion neurons did not changesignificantly in groups of DM+FA40, and DM+FA80 (Fig. 4a, 4c, 4d, and 4b).

\section{Biochemical assays}

Erythrocyte level ofSOD of diabetic group was significantly lower than normal group $(P<0.001)$. On the other hand, these values for folic acidgroups (DM+FA40 and DM+FA80) were not higher than the diabetic group (Fig. 5a).

TheMDAserum level in the diabetic group was significantlyhigher than the normal group $(P<0.01)$ but, serum levels of MDA for folic acid-treated groups ( 40 and $80 \mathrm{mg} / \mathrm{kg} /$ day) were significantly lower than 
that of the diabetic group $(P<0.05)$ after the intervention (Fig. 5b).

Serum level of HCY was increased significantly in the diabetic group compared to the normal group $(P<0.001 ;$ Fig. $5 \mathrm{c})$. Administration of folic acid 40 and $80 \mathrm{mg} / \mathrm{kg} /$ dayshowed a significant decrease in serum level of $\mathrm{HCY}(P<0.001$, and $P<0.0001$, respectively; Fig. $5 \mathrm{C})$.

\section{Discussion}

This study revealed that folic acid does not have a significant effect on prevention and treatment of functional and structural deficits in DAN despite reduced MDA and HCY levels.

In this study, folic acid was administered in two doses of $40 \mathrm{mg} / \mathrm{kg}$ and $80 \mathrm{mg} / \mathrm{kg}$, but neither of them showed a significant response in ABR recordings and spiral ganglion stereology.

In our opinion, spiral ganglion stereology and $A B R$ recordings are indicators that are more closely related to clinical situation than MDA and HCY levels.

The advantage of our study is the histological examination through stereological method and its compliance with functional outcomes in diabetic neuropathies treated with folic acid.

$A B R$ is an important tool for assessing hearing function. Numerous clinical and experimental studies have shown the effect of diabetes on ABR recordings. These changes include an elevation in the hearing threshold and an increase in waves latency as well as a decrease in the amplitude with changes in waveforms[35,36].

Our study showed that 8 weeks' treatment of diabetic rats with folic acid at different doses $(40 \mathrm{mg} / \mathrm{kg}, 80 \mathrm{mg} / \mathrm{kg})$ did not significantly improve hearing threshold and also waves II and V latency as compared to control diabetic rats. There are some differences in rat ABR compared to humans that we have considered in this study. It seems wave II that was generated in the cochlear complex nucleus, is the most prominent in rats ABR recordings[37].

Morphological changes in diabetic auditory neuropathy mainly include atrophy of stria vascularis, thickening of the basilar membrane in the stria vascularis, and a decrease in the number of spiral ganglion neurons[7,38].

Similar to other studies, the histological changes shown in our study following the induction of diabetes in rats included a decrease in the volume of the stria vascularis, spiral ganglion, spiral ligament and a decrease in spiral ganglion neurons. The stereological method we used in this study allows us to more quantitatively and more accurately examine structural and cellular changes in DAN. The structural deficits in DAN are consistent with the functional findings of ABR. In this study, the preventive effect of folic acid on structural changes at different doses $(40 \mathrm{mg} / \mathrm{kg}, 80 \mathrm{mg} / \mathrm{kg})$ was not shown. 
Our study revealed a significant decrease in $\mathrm{HCY}$ levels following folic acid administration in diabetic rats. At higher doses of folic acid $(80 \mathrm{mg} / \mathrm{kg})$, this reduction is more significant. Its role and underlying mechanism in development of vascular complications in diabetes and reducing its levels on complication incidence following treatment are not exactly defined[39,22].

The increased oxidative degradation of nitric oxide(a regulator of endothelial homeostasis) during the process of oxidative stress, is consideredthe presumptive mechanism of endothelial vascular injury in elevated HCY levels[40,41]. Folic acid through its bioactive form, 5-methyltetrahydrofolate, donates a methyl- group forHCY remethylation to methionine $[17,42]$.

Our study showed that plasma MDA levels were significantly increased following folic acid treatment in diabetic rats. This finding is consistent with other findings in experimental studies on the folic acid treatment of neuropathy [10]. Another important finding in this study was the lack of SOD increase following folic acid treatment. These antioxidant enzymes control and eliminate reactive oxygen species (ROS)during oxidative stress in cells [43]. Based on the findings of this study, folic acid lowered plasma $\mathrm{HCY}$ and MDA levels significantly while it had no significant effect on SOD. It may imply that oxidative stress is reduced via a mechanism other than an increase in the amount or action of SOD.

Another perception that can be drawn from these findings is that, due to the lack of improvement in structural and functional disorders in DAN and the lack of significant change in SOD levels, SOD may be a better measure of oxidative stress than HCY and MDA.

It can be deduced that the selected doses of folic acids were not high enough to produce meaningful action on diabetic neuropathy. However, based on our scientific bibliography the selected doses werehigher thanthose applied in similar studies.

\section{Conclusion}

Diabetic auditory neuropathy is one of the serious complications of diabetes that has a serious impact on quality of life. Our study showed that folic acid is not effective in relieving structural and functional disorders in DAN, despite its effect in reducing HCY and MDA. Due to this issue, more studies are needed to find potent drugs for preventing and treating this complication in diabetic patients.

\section{Declarations}

\section{Acknowledgments}

The present article was financially supported by Shiraz University of Medical Sciences (grant No. 16690). The authors would like to thank Shiraz University of Medical Sciences, Shiraz, Iran, and also Ms. Sheryl Thomas-Nikpoor, English language editor, for her invaluable comments in editing this manuscript.

\section{Funding}


Not applicable.

\section{Conflict of interest}

The authors declare that they have no conflict of interest.

\section{Availability of data and materials}

All data is presented within the manuscript file.

\section{Authors' contributions}

A. Doostkam,H. Mirkhani, andK. Iravani conceived and designed research. A. Doostkam, K. Iravani, S. Karbalay-Doust, A. Doosti, and E. Nadimiconducted experiments. A. Doostkam, S. Karbalay-Doust,A. Doosti and E. Nadimi contributed new reagents or analytical tools. A. Doostkam, H. Mirkhani and E. Nadimianalyzed data. A. Doostkamand K. Iravani wrote the manuscript. All authors read and approved the manuscript. The authors declare that all data were generated in-house and that no paper mill was used.

\section{Ethics approval and consent to participate}

Not applicable.

\section{Consent for publication}

Not applicable.

\section{References}

1. Feldman EL, Callaghan BC, Pop-Busui R, Zochodne DW, Wright DE, Bennett DL, Bril V, Russell JW, Viswanathan V (2019) Diabetic neuropathy. Nature reviews Disease primers 5 (1):42. doi:10.1038/s41572-019-0097-9

2. Albers JW, Pop-Busui R (2014) Diabetic neuropathy: mechanisms, emerging treatments, and subtypes. Current neurology and neuroscience reports 14 (8):473. doi:10.1007/s11910-014-0473-5

3. Tousoulis D, Papageorgiou N, Androulakis E, Siasos G, Latsios G, Tentolouris K, Stefanadis C (2013) Diabetes mellitus-associated vascular impairment: novel circulating biomarkers and therapeutic approaches. Journal of the American College of Cardiology 62 (8):667-676.

doi:10.1016/j.jacc.2013.03.089

4. Dewanjee S, Das S, Das AK, Bhattacharjee N, Dihingia A, Dua TK, Kalita J, Manna P (2018) Molecular mechanism of diabetic neuropathy and its pharmacotherapeutic targets. European journal of pharmacology 833:472-523. doi:10.1016/j.ejphar.2018.06.034 
5. Sifuentes-Franco S, Pacheco-Moisés FP, Rodríguez-Carrizalez AD, Miranda-Díaz AG (2017) The Role of Oxidative Stress, Mitochondrial Function, and Autophagy in Diabetic Polyneuropathy. Journal of diabetes research 2017:1673081. doi:10.1155/2017/1673081

6. Feldman EL, Nave KA, Jensen TS, Bennett DLH (2017) New Horizons in Diabetic Neuropathy: Mechanisms, Bioenergetics, and Pain. Neuron 93 (6):1296-1313. doi:10.1016/j.neuron.2017.02.005

7. Akinpelu OV, Ibrahim F, Waissbluth S, Daniel SJ (2014) Histopathologic changes in the cochlea associated with diabetes mellitus--a review. Otology \& neurotology : official publication of the American Otological Society, American Neurotology Society [and] European Academy of Otology and Neurotology 35 (5):764-774. doi:10.1097/mao.0000000000000293

8. Rance G, Chisari D, O'Hare F, Roberts L, Shaw J, Jandeleit-Dahm K, Szmulewicz D (2014) Auditory neuropathy in individuals with Type 1 diabetes. Journal of neurology 261 (8):1531-1536. doi:10.1007/s00415-014-7371-2

9. Doostkam A, Mirkhani H, Iravani K, Karbalay-Doust S, Zarei K (2020) Effect of Rutin on Diabetic Auditory Neuropathy in an Experimental Rat Model. Clinical and experimental otorhinolaryngology. doi:10.21053/ceo.2019.02068

10. Yilmaz M, Aktug H, Oltulu F, Erbas O (2016) Neuroprotective effects of folic acid on experimental diabetic peripheral neuropathy. Toxicology and industrial health 32 (5):832-840.

doi:10.1177/0748233713511513

11. Wang D, Zhai JX, Liu DW (2017) Serum folate, vitamin B12 levels and diabetic peripheral neuropathy in type 2 diabetes: A meta-analysis. Molecular and cellular endocrinology 443:72-79.

doi:10.1016/j.mce.2017.01.006

12. Han Y, Wang M, Shen J, Zhang Z, Zhao M, Huang J, Chen Y, Chen Z, Hu Y, Wang Y (2018) Differential efficacy of methylcobalamin and alpha-lipoic acid treatment on symptoms of diabetic peripheral neuropathy. Minerva endocrinologica 43 (1):11-18. doi:10.23736/s0391-1977.16.02505-0

13. Várkonyi T, Körei A, Putz Z, Martos T, Keresztes K, Lengyel C, Nyiraty S, Stirban A, Jermendy G, Kempler P (2017) Advances in the management of diabetic neuropathy. Minerva medica 108 (5):419-437. doi:10.23736/s0026-4806.17.05257-0

14. Enderami A, Zarghami M, Darvishi-Khezri H (2018) The effects and potential mechanisms of folic acid on cognitive function: a comprehensive review. Neurological sciences : official journal of the Italian Neurological Society and of the Italian Society of Clinical Neurophysiology 39 (10):1667-1675. doi:10.1007/s10072-018-3473-4

15. Couto MR, Gonçalves P, Catarino T, Araújo JR, Correia-Branco A, Martel F (2012) The effect of oxidative stress upon the intestinal uptake of folic acid: in vitro studies with Caco-2 cells. Cell biology and 
toxicology 28 (6):369-381. doi:10.1007/s10565-012-9228-8

16. Ferrazzi E, Tiso G, Di Martino D (2020) Folic acid versus 5- methyl tetrahydrofolate supplementation in pregnancy. European journal of obstetrics, gynecology, and reproductive biology 253:312-319. doi:10.1016/j.ejogrb.2020.06.012

17. Imbard A, Benoist JF, Blom HJ (2013) Neural tube defects, folic acid and methylation. International journal of environmental research and public health 10 (9):4352-4389. doi:10.3390/ijerph10094352

18. Field MS, Stover PJ (2018) Safety of folic acid. Annals of the New York Academy of Sciences 1414 (1):59-71. doi:10.1111/nyas.13499

19. van Gool JD, Hirche H, Lax H, De Schaepdrijver L (2018) Folic acid and primary prevention of neural tube defects: A review. Reproductive toxicology (Elmsford, NY) 80:73-84.

doi:10.1016/j.reprotox.2018.05.004

20. Helzner EP, Contrera KJ (2016) Type 2 Diabetes and Hearing Impairment. Current diabetes reports 16 (1):3. doi:10.1007/s11892-015-0696-0

21. Mursleen MT, Riaz S (2017) Implication of homocysteine in diabetes and impact of folate and vitamin B12 in diabetic population. Diabetes \& metabolic syndrome 11 Suppl 1:S141-s146. doi:10.1016/j.dsx.2016.12.023

22. Koller A, Szenasi A, Dornyei G, Kovacs N, Lelbach A, Kovacs I (2018) Coronary Microvascular and Cardiac Dysfunction Due to Homocysteine Pathometabolism; A Complex Therapeutic Design. Current pharmaceutical design 24 (25):2911-2920. doi:10.2174/1381612824666180625125450

23. Damanik J, Mayza A, Rachman A, Sauriasari R, Kristanti M, Agustina PS, Angianto AR, Prawiroharjo P, Yunir E (2019) Association between serum homocysteine level and cognitive function in middle-aged type 2 diabetes mellitus patients. PloS one 14 (11):e0224611. doi:10.1371/journal.pone.0224611

24. Wang Y, Branicky R, Noë A, Hekimi S (2018) Superoxide dismutases: Dual roles in controlling ROS damage and regulating ROS signaling. The Journal of cell biology 217 (6):1915-1928. doi: $10.1083 /$ jcb. 201708007

25. Islam MT (2017) Oxidative stress and mitochondrial dysfunction-linked neurodegenerative disorders. Neurological research 39 (1):73-82. doi:10.1080/01616412.2016.1251711

26. Frijhoff J, Winyard PG, Zarkovic N, Davies SS, Stocker R, Cheng D, Knight AR, Taylor EL, Oettrich J, Ruskovska T, Gasparovic AC, Cuadrado A, Weber D, Poulsen HE, Grune T, Schmidt HH, Ghezzi P (2015) Clinical Relevance of Biomarkers of Oxidative Stress. Antioxidants \& redox signaling 23 (14):1144-1170. doi:10.1089/ars.2015.6317 
27. Rostami S, Momeni Z, Behnam-Rassouli M, Rooholamin S (2013) A comparative study on the effects of type I and type II diabetes on learning and memory deficit and hippocampal neuronal loss in rat. Minerva endocrinologica 38 (3):289-295

28. Kuse H, Ogawa T, Nakamura N, Nakayama Y, Nakakarumai A, Komori C, Tsuda Y, Matsushima K, Nakamura A, Tamura K (2011) Changes in auditory brainstem response (ABR) in Kanamycin-induced auditory disturbance model rats. The Journal of toxicological sciences 36 (6):835-841. doi:10.2131/jts.36.835

29. Márquez-Gamiño S, Sotelo F, Sosa M, Caudillo C, Holguín G, Ramos M, Mesa F, Bernal J, Córdova T (2008) Pulsed electromagnetic fields induced femoral metaphyseal bone thickness changes in the rat. Bioelectromagnetics 29 (5):406-409. doi:10.1002/bem.20396

30. Rusznák Z, Szucs G (2009) Spiral ganglion neurones: an overview of morphology, firing behaviour, ionic channels and function. Pflugers Archiv : European journal of physiology 457 (6):1303-1325. doi:10.1007/s00424-008-0586-2

31. Kristiansen SL, Nyengaard JR (2012) Digital stereology in neuropathology. APMIS : acta pathologica, microbiologica, et immunologica Scandinavica 120 (4):327-340. doi:10.1111/j.1600-0463.2012.02889.x

32. Schettino AE, Lauer AM (2013) The efficiency of design-based stereology in estimating spiral ganglion populations in mice. Hearing research 304:153-158. doi:10.1016/j.heares.2013.07.007

33. Gundersen HJ, Bagger P, Bendtsen TF, Evans SM, Korbo L, Marcussen N, Møller A, Nielsen K, Nyengaard JR, Pakkenberg B, et al. (1988) The new stereological tools: disector, fractionator, nucleator and point sampled intercepts and their use in pathological research and diagnosis. APMIS : acta pathologica, microbiologica, et immunologica Scandinavica 96 (10):857-881. doi:10.1111/j.16990463.1988.tb00954.x

34. Gundersen HJ, Bendtsen TF, Korbo L, Marcussen N, Møller A, Nielsen K, Nyengaard JR, Pakkenberg B, Sørensen FB, Vesterby A, et al. (1988) Some new, simple and efficient stereological methods and their use in pathological research and diagnosis. APMIS : acta pathologica, microbiologica, et immunologica Scandinavica 96 (5):379-394. doi:10.1111/j.1699-0463.1988.tb05320.x

35. Baiduc RR, Helzner EP (2019) Epidemiology of Diabetes and Hearing Loss. Seminars in hearing 40 (4):281-291. doi:10.1055/s-0039-1697643

36. Tsuda J, Sugahara K, Hori T, Kanagawa E, Takaki E, Fujimoto M, Nakai A, Yamashita H (2016) A study of hearing function and histopathologic changes in the cochlea of the type 2 diabetes model Tsumura Suzuki obese diabetes mouse. Acta oto-laryngologica 136 (11):1097-1106.

doi:10.1080/00016489.2016.1195012 
37. Alvarado JC, Fuentes-Santamaría V, Jareño-Flores T, Blanco JL, Juiz JM (2012) Normal variations in the morphology of auditory brainstem response (ABR) waveforms: a study in Wistar rats. Neuroscience research 73 (4):302-311. doi:10.1016/j.neures.2012.05.001

38. Meyer zum Gottesberge AM, Massing T, Sasse A, Palma S, Hansen S (2015) Zucker diabetic fatty rats, a model for type 2 diabetes, develop an inner ear dysfunction that can be attenuated by losartan treatment. Cell and tissue research 362 (2):307-315. doi:10.1007/s00441-015-2215-7

39. Muzurović E, Kraljević I, Solak M, Dragnić S, Mikhailidis DP (2021) Homocysteine and diabetes: Role in macrovascular and microvascular complications. Journal of diabetes and its complications 35 (3):107834. doi:10.1016/j.jdiacomp.2020.107834

40. Jamwal S, Sharma S (2018) Vascular endothelium dysfunction: a conservative target in metabolic disorders. Inflammation research : official journal of the European Histamine Research Society [et al] 67 (5):391-405. doi:10.1007/s00011-018-1129-8

41. Esse R, Barroso M, Tavares de Almeida I, Castro R (2019) The Contribution of Homocysteine Metabolism Disruption to Endothelial Dysfunction: State-of-the-Art. International journal of molecular sciences 20 (4). doi:10.3390/ijms20040867

42. Zaric BL, Obradovic M, Bajic V, Haidara MA, Jovanovic M, Isenovic ER (2019) Homocysteine and Hyperhomocysteinaemia. Current medicinal chemistry 26 (16):2948-2961.

doi:10.2174/0929867325666180313105949

43. He L, He T, Farrar S, Ji L, Liu T, Ma X (2017) Antioxidants Maintain Cellular Redox Homeostasis by Elimination of Reactive Oxygen Species. Cellular physiology and biochemistry : international journal of experimental cellular physiology, biochemistry, and pharmacology 44 (2):532-553.

doi:10.1159/000485089

\section{Figures}




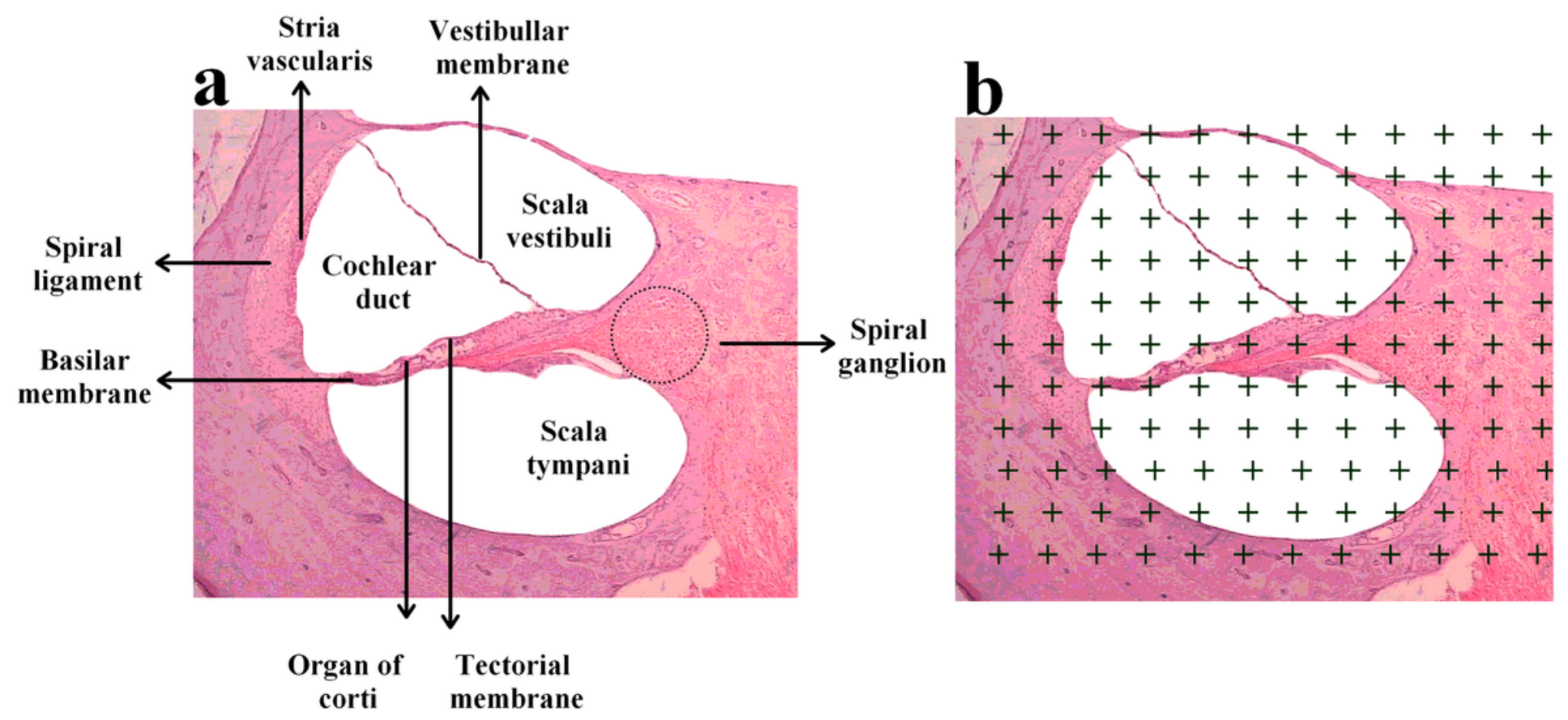

\section{Figure 1}

Stereologicalmethodsestimation of the stria vascularis,spiral ligament and spiral ganglion volumes. The location of striavascularis, spiral ligament and spiral ganglion of cochlea displayed on the histological section (a). The volume of thestriavascularis, spiral ligament and spiral ganglion was evaluated by Cavalieri's principle and point-counting technique (b).
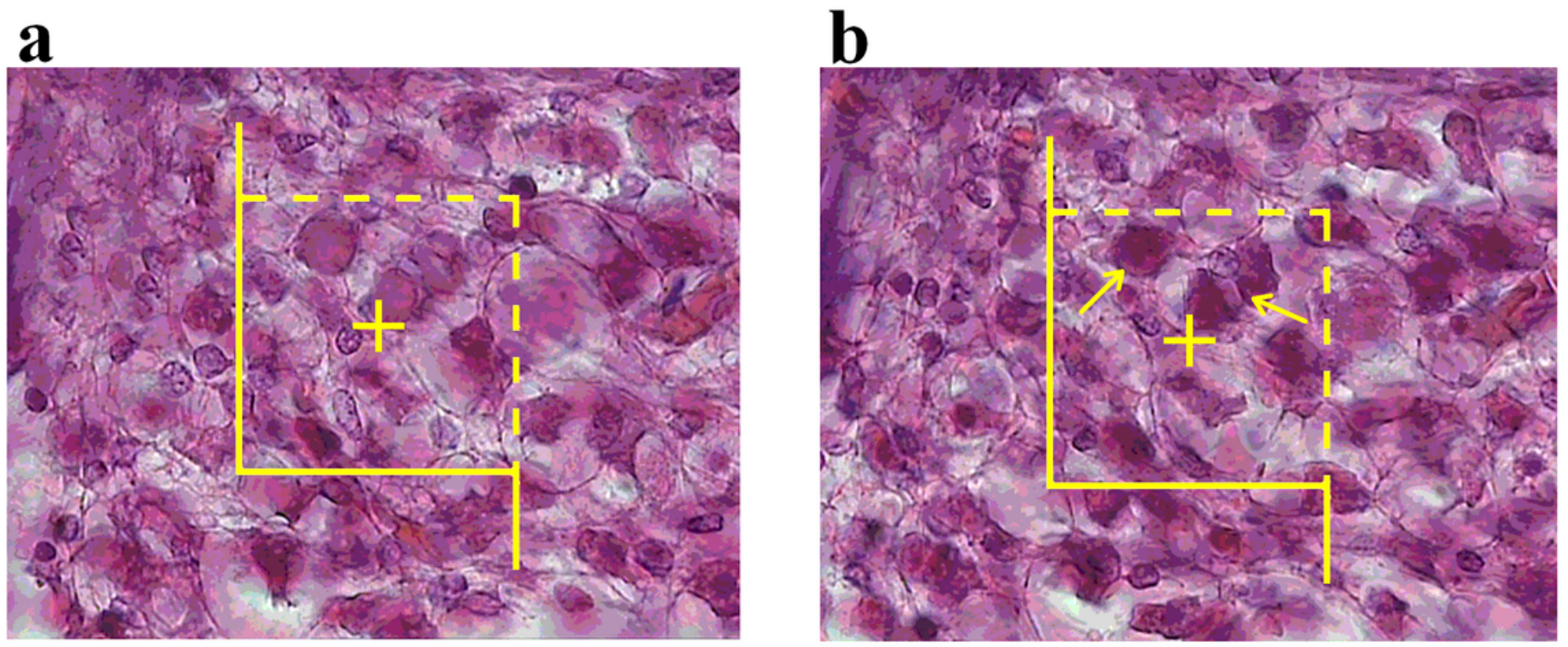

\section{Figure 2}

Stereological technique estimation of the numbers of spiral ganglion cells. Estimated number of ganglion cells assessed using optical dissector method. The cells nuclei that appeared in the high focus during scanning of the height of the disector were counted (the arrow) (a\&b). 

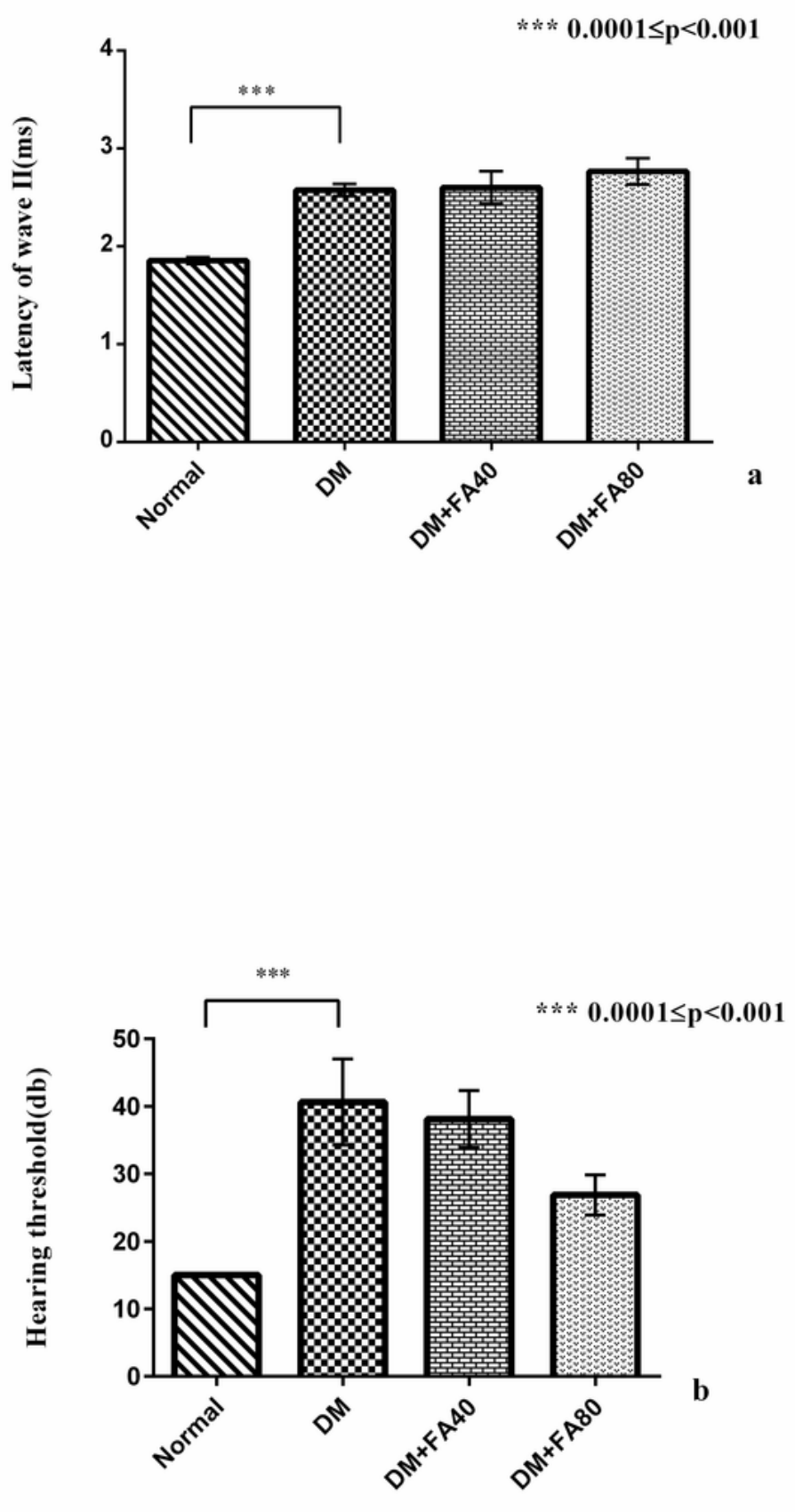

Figure 3

Latency of wave II (a), andHearing threshold (b) in the normal, DM, DM+FA40, and DM+FA80 groups. $\star \star \star$ indicates $\mathrm{P}<0.001$ vs. diabetic group. 

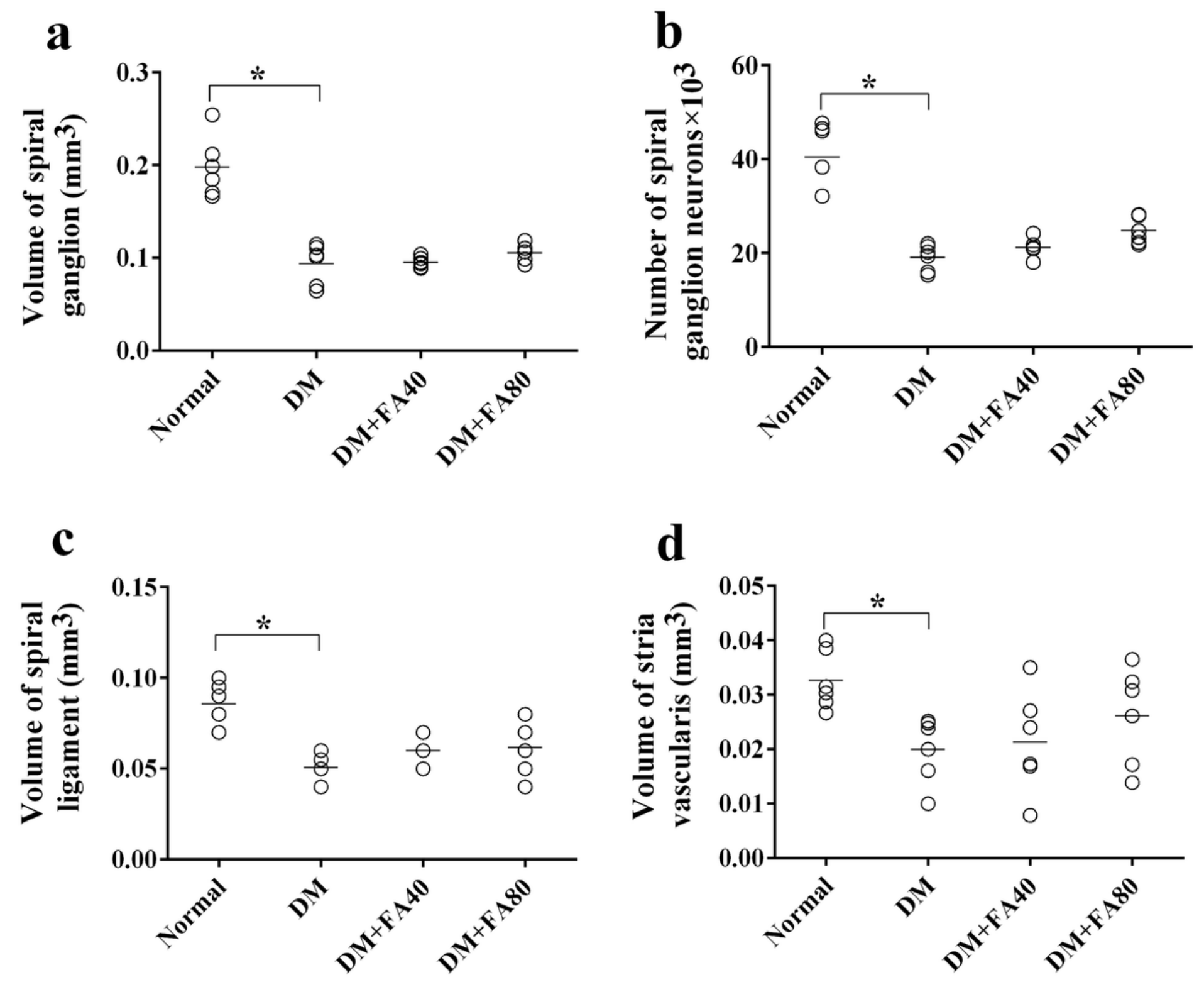

Figure 4

The aligned dot plot of the volumes of the spiral ganglion(a), spiral ligament(c), striavascularis(d), and number of spiral ganglion neurons(b)in the normal, DM, DM+FA40, and DM+FA80 groups. Each dot represented an animal and the horizontal bar is the mean of the listed parameters. ${ }^{*}$ indicates $\mathrm{P}<0.05 \mathrm{vs}$. diabetic group. 

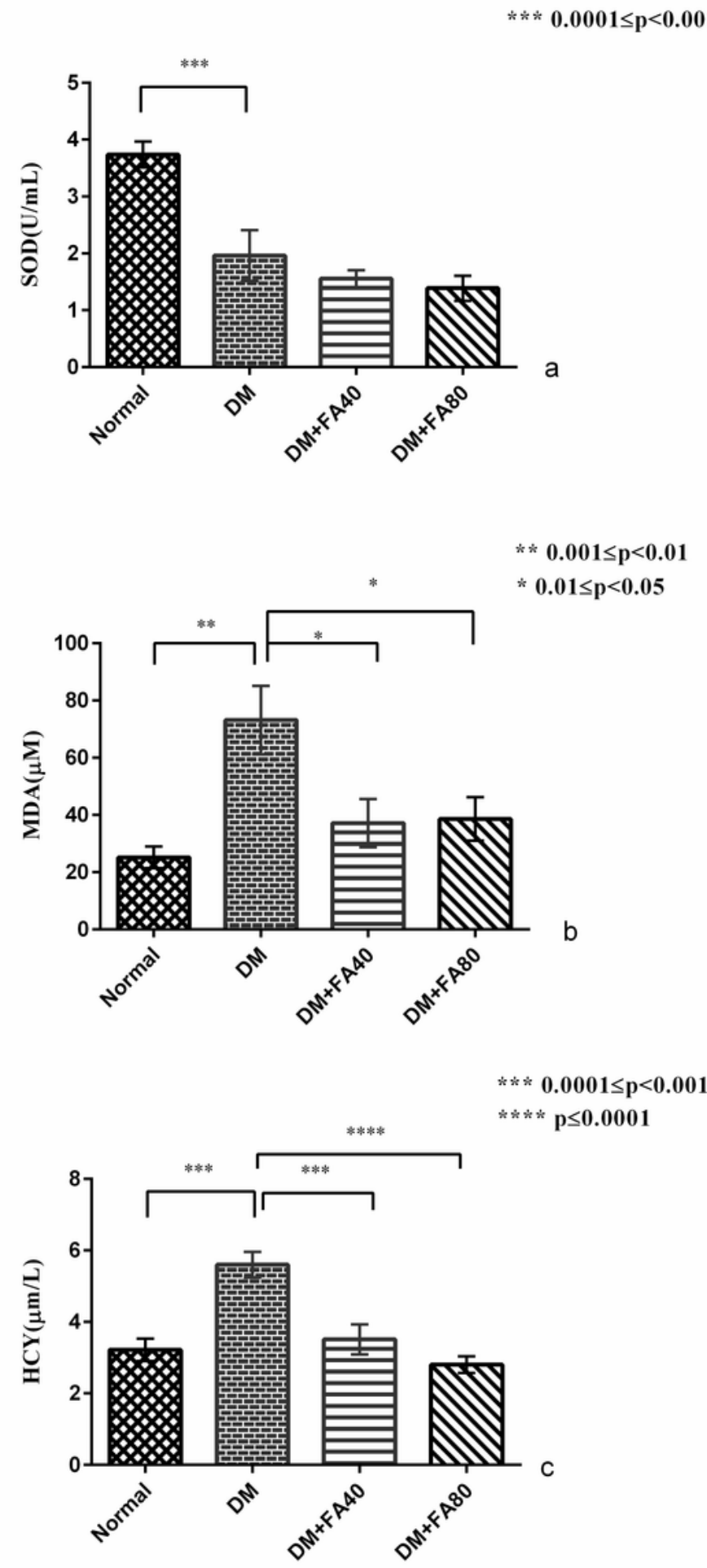

Figure 5

Serumlevel of $\operatorname{SOD}(\mathrm{a}), \mathrm{MDA}(\mathrm{b})$, and $\mathrm{HCY}$ (c) in the normal, DM, DM+FA40, and DM+FA80 groups. *indicates $P<0.05 \mathrm{vs}$. diabetic group. **indicates $P<0.01$ vs. diabetic group. $* \star \star$ indicates $P<0.001 \mathrm{vs}$. diabetic group. ${ }^{\star \star \star \star}$ indicates $\mathrm{P}<0.0001$ vs. diabetic group.

\section{Supplementary Files}


This is a list of supplementary files associated with this preprint. Click to download.

- AllofFolicaciddata.pzfx 